\title{
AUTONOMÍA Y DIÁLOGO: ANOTACIONES OPTIMISTAS SOBRE DARWINISMO Y RELIGIÓN
}

\section{AUTONOMY AND DIALOGUE: SOME OPTIMISTIC NOTES ON DARWINISM AND RELIGION}

\author{
Alfredo MARCOS \\ Departamento de Filosofía \\ Universidad de Valladolid
}

\begin{abstract}
RESUMEN: La relación del darwinismo con las creencias religiosas viene siendo desde la aparición de El origen de las especies un asunto polémico. El debate se viene produciendo en dos niveles. En el primer nivel se plantea como un enfrentamiento entre evolucionismo y creacionismo. En un segundo (meta)nivel se discute si existe un inexorable enfrentamiento entre darwinismo y cristianismo, o si, por el contrario, puede existir compatibilidad. Las obras recientes de Michael Ruse, Francisco Ayala y Mariano Artigas abogan por la compatibilidad. Trataremos en lo que sigue de presentar el estado de la cuestión del mencionado (meta)debate a partir de las nuevas ideas y documentos aportados por estos autores ${ }^{1}$.
\end{abstract}

PALABRAS ClaVE: Creacionismo, darwinismo, diseño inteligente, evolucionismo, religión.

ABSTRACT: The relationship between Darwinism and religion is a contentious issue since the publication of the Origin of Species. The debate comes at two levels. At the first one it appears as a confrontation between Evolutionism and Creationism. At a second level — which is in fact meta-level—, we

\footnotetext{
${ }^{1}$ Sirva el presente artículo como recuerdo y homenaje al profesor Mariano Artigas, fallecido hace apenas tres años. Asimismo, quiero expresar mi agradecimiento por sus comentarios a Ignacio Núnez de Castro y a Sixto Castro.
} 
discuss whether or not there must be an inexorable conflict between Darwinism and Christianity. Recent works by Michael Ruse, Francisco Ayala and Mariano Artigas advocate for compatibility. Here I try to present the state of the art regarding the above mentioned meta-debate taking into account the new ideas and documents produced by these authors.

KEYWORDS: Creationism, Darwinism, evolutionism, intelligent design, religion.

\section{Introducción}

$\mathrm{Al}$ igual que la música, la poesía o el derecho, la ciencia y la religión son altas manifestaciones del espíritu humano. Cada una de ellas debe disponer de su esfera de autonomía, de libertad de juicio y de acción. Esta aspiración a la autonomía constituyó una de las marcas más características de la modernidad. Fue Kant quien estableció con mayor claridad la necesidad de autonomía de los ámbitos que componen la esfera del saber. Pero la reclamación de autonomía venía de mucho más atrás. Como señala Evandro Agazzi (1992), ya Tomás de Aquino, en el siglo XIII, argumentó a favor de la autonomía de la filosofía respecto de la teología. Las cuestiones filosóficas, diría, deben afrontarse y juzgarse desde la propia razón. Más tarde Galileo abogaría enérgicamente por la autonomía de la ciencia. En el caso Galileo no se dio principalmente una lucha entre ciencia y religión, sino de un enfrentamiento entre dos formas antitéticas de concebir las relaciones ciencia-religión. Galileo, hemos dicho, abogaba por la mutua autonomía, mientras que sus oponentes buscaban la dependencia jerárquica. No hubo en Galileo ninguna animadversión hacia lo religioso, nunca abjuró de su condición de cristiano, ni, por supuesto, de la de científico. Sí pensaba, en cambio, que a la ciencia se le debe reconocer su propio espacio, su ámbito de autonomía en la acción y en el juicio. Esta idea se resume a veces en una cita galileana que se ha hecho célebre: «El Espíritu Santo intentó enseñarnos cómo ir al cielo, no cómo van los cielos». Es probable que el propio científico tomase la frase del cardenal Cesar Baronio. Esta idea concuerda, por cierto, con la exégesis contemporánea de los géneros bíblicos, entre los que no se encuentra, desde luego, el artículo científico. En la misma línea señalada, Maquiavelo abogó por la autonomía de lo político, los economistas liberales británicos hicieron otro tanto con la economía y el propio Kant con el arte. 
Hay que aclarar inmediatamente que autonomía no quiere decir desconexión, y mucho menos hostilidad. No se trata de que ciencia, arte, religión, moral, política o economía se den mutuamente la espalda. Tampoco es cuestión, claro está, de que se enzarcen en luchas cuando menos estériles. La autonomía moderna es compatible, o debería serlo, con la mutua conexión, con la comunicación, la colaboración y el diálogo. Este delicado punto de equilibrio no siempre es fácil de conseguir. La experiencia histórica nos enseña que es más fácil deslizarse hacia la mutua ignorancia, hacia las imposiciones jerárquicas o incluso hacia la beligerancia. El logro y mantenimiento de un punto de equilibrio como el referido requiere grandes dosis de respeto, de tolerancia, de humildad intelectual, de creatividad y, sobre todo, de trabajo. El ejemplo de Tomás de Aquino de nuevo viene al caso: toda una biografía intelectual volcada en la labor de tejer conexiones entre la tradición judeocristiana y la mejor ciencia de su momento, la aristotélica, sin violentar ninguno de los dos polos, sin estrechar sus márgenes de autonomía y sin renunciar al mutuo enriquecimiento. El affaire Galileo, por el contrario, muestra lo mal que se pueden llegar a hacer las cosas, lo equivocado que puede resultar el intento de someter jerárquicamente un ámbito a otro.

Y prácticamente da igual cuál sea el uno y cuál el otro. El resultado siempre es catastrófico. Cuando se intenta someter la ciencia a la teología, Galileo, el creador de la nueva física, acaba tristemente silenciado en arresto domiciliario. Cuando es la política la que se impone sobre la ciencia, Lavoisier, el creador de la nueva química, resulta guillotinado al grito de «la república no necesita científicos». Cuando la religión se impone sobre la política algunas mujeres mueren lapidadas. Cuando, a la inversa, la política subyuga a la religión, los campos de concentración no dan abasto. Y cada vez que hemos puesto la tecnociencia por encima de todo y de todos, no hemos logrado sino sacar a paseo unos cuantos monstruos frankensteinianos.

El anhelo de autonomía dio nervio y legitimidad al proyecto moderno. Los logros en esa línea no deberían perderse. Pero tal vez nosotros, postmodernos ${ }^{2}$, queramos hoy día remediar los excesos que nos han llevado a la desconexión total, al autismo de las dos culturas, a lo que Bertrand Russell llamó la esqui-

2 El término "postmoderno» lo empleo aquí en un sentido sencillamente cronológico. La postmodernidad es simplemente la época que sucede a la modernidad, y que puede albergar, y de hecho alberga, una pléyade de diferentes posiciones filosóficas. 
zofrenia del hombre moderno. Quizá busquemos reparar los daños causados por el cientificismo en su intento de nuevas imposiciones jerárquicas. Puede que prefiramos el diálogo al enfrentamiento entre los diversos ámbitos del espíritu humano.

Esta voluntad de diálogo cobró visibilidad internacional en el conocido debate entre Jürgen Habermas y Joseph Ratizinger, sostenido el día 19 de enero del 2004 en la Academia Católica de Munich. La religión, en opinión de Habermas, debe abandonar la aspiración a monopolizar la interpretación y a organizar todos los aspectos de la vida. Al mismo tiempo, al Estado constitucional le conviene ser respetuoso con todas las fuentes culturales de las que se nutre, como es el caso de la religión. Por su parte el entonces cardenal Ratzinger sostenía que los ciudadanos secularizados no deben negarles a las visiones religiosas del mundo un potencial de verdad. Ambos pensadores, a pesar de sus diferencias, apuntan conjuntamente hacia esa trabajosa posición de equilibrio de la que hablamos: autonomía y diálogo.

Ya tenemos contexto y perspectiva para formular aquí la pregunta que ha de guiarnos en adelante. Cuando se cumplen 150 años de la publicación de El origen de las especies, ¿es posible llevar el debate sobre evolución y religión a un punto de equilibrio sensato?

Pocos debates han resultado tan conflictivos, pocos han producido más calor y menos luz que este acerca de las relaciones entre darwinismo y religión, pocos han llegado a estar tan mal planteados. Y sin embargo, en mi opinión, estamos hoy día ante un panorama favorable. A punto de convertir una larga serie de malentendidos en un diálogo fructífero. Expondré a continuación los antecedentes históricos de la polémica (apartados 2 y 3), y trataré después de dar base a las apreciaciones optimistas refiriéndome a algunos textos recientes de autores como Ayala, Ruse y Artigas (apartado 4), para finalizar con unas sumarias conclusiones (apartado 5).

\section{Antecedentes históricos}

Entre los años 1831 y 1836 Darwin permaneció embarcado en el Beagle, en un viaje de circunnavegación que le permitió entrar en contacto con la flora, la 
fauna y las configuraciones geológicas de una buena parte de nuestro planeta. Embarcó con el primer volumen de los Principios de Geología de Lyell en mano, y durante el viaje recibió el segundo volumen. Lyell exponía en este libro su teoría geológica, cuya esencia se encierra en la fórmula «equilibrio dinámico». La construcción y la destrucción de las estructuras geológicas se compensan mutuamente, erosión y sedimentación, aguas y vientos, volcanes y terremotos, danzan eternamente en torno a un punto de equilibro que en líneas generales se mantiene. Los seres vivos resultan ser también agentes de configuración geológica. Ahora bien, el registro fósil nos informa de que muchos de ellos se han extinguido hace milenios o eones. ¿Cómo podría compensarse esta pérdida, sin desviación notable del equilibrio dinámico? Indudablemente con la aparición de nuevas especies de vivientes. Pero, ¿cómo podríamos explicar el origen de las nuevas especies dentro de un marco naturalista, sin salirnos del tipo de causas que estudia la ciencia?

El joven geólogo Charles Darwin, a fuerza de observar la distribución de arrecifes y volcanes se fue convirtiendo poco a poco al lyellismo. Es cierto que esta teoría da cuenta con rigor y acierto de múltiples fenómenos de los que constató en su viaje. Pero deja abierta la pregunta por el origen de las especies. Ni el propio Lyell se atrevió con ella. Pero sí Darwin a su regreso a Inglaterra. Se puede decir que a finales de la década de los 30 o principios de la de los 40 bullía ya en su mente la teoría de la evolución por selección natural. Sin embargo se cuidó de publicar nada al respecto. ¿Qué lo retuvo? Darwin esperaba acumular datos favorables a su hipótesis, de modo que obtuviese un incontestable respaldo empírico. Buscaba además rodearse de un núcleo de científicos bien ubicados que pudiesen al menos entender su respuesta al «enigma de los enigmas» y que estuviesen en posición de apoyarle públicamente.

Tanto el acopio de datos, como la estrategia sociológica llevarían su tiempo. Por otro lado, no quiso ser confundido con la charlatanería de los Vestiges, obra publicada anónimamente en 1844, finalmente atribuida a Robert Chalmers, en la que se hacía una defensa del evolucionismo pobremente argumentada. Entre unas cosas y otras el tiempo pasaba, hasta que en junio 1858 Darwin recibió una carta de un ignoto naturalista británico llamado Alfred Wallace.

Tras una expedición amazónica, Wallace había perdido las colecciones de especímenes en el incendio del barco que le devolvía a Inglaterra. No perdió, 
sin embargo, la vida, ni el empuje para volver a la carga. Esta vez en el archipiélago Malayo. Desde allí escribió a Darwin. Como Darwin, él también había leído a Lyell y a Malthus. Y él también, independientemente, había llegado a concebir la teoría de la evolución por selección natural. En pocas páginas la exponía y la sometía a la consideración del ya prestigioso y consagrado Charles Darwin. Ni que decir tiene que la carta de Wallace puso inmediatamente en movimiento a Darwin, quien pidió consejo a Lyell. Éste aconsejó la presentación conjunta de la nueva teoría evolucionista por parte de Darwin y de Wallace ante la Sociedad Linneana de Londres. Así se hizo el 29 de diciembre de 1858. Unos meses más tarde, el 24 de noviembre de 1859, Darwin publicaba El origen de las especies.

Desde el comienzo la obra resultó tan exitosa como polémica. Desencadenó debates en el medio académico y científico, también disputas de carácter político y social y, por supuesto, disensos en el plano religioso. En resumen, podríamos decir que el componente evolucionista fue aceptado rápidamente por la comunidad científica, no así el componente seleccionista, que fue admitido más lentamente, como relata el historiador Peter Bowler (Bowler, 1985). Fuera de la comunidad científica, ambos componentes siguieron resultando polémicos aún décadas más tarde. Aquí me ocuparé tan sólo del debate en el plano religioso.

Algunos antecedentes son poco prometedores para quien busque una feroz disputa entre ciencia y religión: el propio Darwin habla con respeto del hecho religioso. Él mismo valoró seriamente la posibilidad de convertirse en clérigo anglicano. «Tras haber pasado dos cursos en Edimburgo — nos informa Charles Darwin en su Autobiografía (Darwin, 1887, 24-253) —, mi padre se percató, o se enteró por mis hermanas, de que no me agradaba la idea de ser médico, así que me propuso hacerme clérigo [...] Pedí algún tiempo para considerarlo, pues, por lo poco que había oído o pensado sobre la materia, sentía escrúpulos acerca de la declaración de mi fe en todos los dogmas de la Iglesia Anglicana, aunque, por otra parte, me agradaba la idea de ser cura rural. Por consiguiente leí con atención Pearson on the Creed (Pearson: Acerca del Credo) y otros cuantos libros de teología [...] me convencí inmediatamente de que debía aceptar nuestro credo sin reservas. Considerando la ferocidad con que he sido atacado por los orto-

\footnotetext{
${ }^{3}$ Cuando existe traducción al español, la paginación citada corresponde a esta.
} 
doxos, parece cómico que alguna vez pensara en ser clérigo. Y no es que yo renunciara expresamente a esta intención ni al deseo de mi padre, dicha intención murió de muerte natural cuando, al dejar Cambridge, me uní al Beagle en calidad de naturalista».

El talante de Darwin no parece ser muy belicoso en materia de religión. De hecho nunca se presentó como antirreligioso, sino simplemente como agnóstico (Núñez de Castro, 1996), y no deberíamos traicionar su carácter presentándolo hoy como la versión decimonónica de los cientificistas contemporáneos.

Sus dos grandes obras, El origen de las especies y El origen del hombre concluyen con sendos párrafos que podría suscribir actualmente cualquier persona religiosa: «Hay grandeza en esta concepción de que la vida —afirma en El origen de las especies $(1859,777)$ - con sus diferentes facultades, fue originalmente alentada por el Creador en unas cuantas formas o en una sola, y que, mientras este planeta ha ido girando según la constante ley de la gravitación, se han desarrollado y se están desarrollando, a partir de un comienzo tan sencillo, infinidad de formas cada vez más bellas y maravillosas».

«Debemos, sin embargo, reconocer — concluye en El origen del hombre (1871, 805-6) - que el hombre, según me parece, con todas sus nobles cualidades, con la simpatía que siente por los más degradados de sus semejantes, con la benevolencia que hace extensiva, no ya a los otros hombres, sino hasta a las criaturas inferiores, con su inteligencia semejante a la de Dios, con cuyo auxilio ha penetrado los movimientos y constitución del sistema solar — con todas estas exaltadas facultades - lleva en su hechura corpórea el sello indeleble de su ínfimo origen».

Esto no quiere decir que no existan dificultades en la conciliación de puntos de vista. Se han presentado escollos básicamente en cuanto a la compatibilidad del darwinismo con el relato bíblico del Génesis. Obviamente, una interpretación estrechamente literalista de estos pasajes obligaría a elegir entre lo uno y lo otro. Pero también es obvio que una interpretación de este cariz no es la única posible, ni la más sólida intelectualmente, ni siquiera la más comúnmente admitida entre los cristianos. De igual modo, puede darse conflicto en lo tocante al origen y naturaleza del ser humano; así como en algunas cuestiones relativas a la moral y a la libertad como su condición de posibilidad. 
En un plano todavía más profundo, el naturalismo y la ausencia de sentido del devenir mundano, supuestamente promocionados por el darwinismo, no dejarían de chocar con la idea cristiana de una realidad sobrenatural y de un cosmos pleno de finalidad y de sentido. Podríamos responder que ni la antropología determinista ni el nihilismo son consecuencias necesarias de la teoría darwinista de la evolución, como no lo son el darwinismo social ni la moral del más fuerte. Con todo, hay que reconocer que nos hallamos ante dificultades reales, mas no insalvables a base de trabajo y colaboración intelectual.

Históricamente las disputas comenzaron en fecha tan temprana como el 30 de junio de 1860. Ese día se produjo en el Oxford University Museum el famoso debate entre el darwinista Thomas Henry Huxley y el obispo Samuel Wilberforce. No existen actas literales del debate, por lo tanto nadie sabe a ciencia cierta qué fue lo que allí se dijo. El relato más común nos llega a través de un texto del propio Huxley editado por su hijo. Se ha popularizado la versión según la cual Wilberforce llegó a preguntar a Huxley si descendía del mono por línea materna o paterna. Al parecer los reflejos dialécticos de Huxley le llevaron a responder que no le avergonzaría estar emparentado con monos, pero sí con personas que utilizan sus capacidades para oscurecer la verdad, en referencia clara al propio Wilberforce.

El debate, a estas alturas, queda ya en un terreno intermedio entre la historia y la leyenda. El problema es que con demasiada frecuencia se ha presentado como el enfrentamiento frontal entre dos fuerzas antagónicas, la religión y la ciencia, la oscuridad y la luz, con final triunfante para esta última. Sin embargo, Michael Ruse $(2001,5)$, en un reciente libro le quita hierro al asunto: «Informes de la época sugieren que todo el mundo se divirtió enormemente y que se fueron a cenar todos juntos, alegremente, al terminar». Digamos que el ambiente dramático de choque irreparable pertenece más a las versiones posteriores, confeccionadas para la utilización sesgada del incidente.

No sólo en Gran Bretaña se produjo oposición al darwinismo por motivos religiosos, también en los Estados Unidos se dio esta reacción. En 1874 el teólogo Charles Hodge publicó What is Darwinism? Este libro fija los puntos de conflicto en el naturalismo, que inmediatamente identifica con ateísmo, y en la cuestión del diseño. Hay que recordar la vigencia extraordinaria que tenía en esta época en ámbitos anglicanos el argumento del diseño, tal y como fue formula- 
do en 1802 por el filósofo británico William Paley. Según su analogía, del mismo modo que nadie duda, a la vista de un reloj, de que ha sido diseñado por un relojero, nadie debería dudar, a la vista de un organismo, de que ha sido diseñado por el Creador.

Se puede entender perfectamente que los teólogos anglicanos de la época de Darwin tomasen su teoría como un ataque frontal al argumento del diseño, y, en consecuencia, como un deslizamiento hacia el ateísmo. Por supuesto, también los defensores del ateísmo pudieron ver en Darwin un aliado de su causa. De un modo u otro, el reloj de Paley ha marcado década tras década el ritmo del debate entre evolución y creación, hasta la publicación en 1986 de El relojero ciego, por parte de Richard Dawkins. Como veremos más abajo, todo esto no ha impedido que eminentes teólogos hayan argumentado a favor de la compatibilidad entre evolución y creación, ni que algunos de los más prestigiosos científicos darwinistas hayan seguido fieles a sus creencias religiosas.

El debate se ha prolongado a lo largo del siglo XX sobre todo en los Estados Unidos. Algunos momentos del mismo se han convertido ya en clásicos. Por ejemplo, el juicio celebrado en los años veinte, en Tennessee, contra el maestro John Thomas Scopes, acusado de enseñar el darwinismo a sus alumnos. El hecho histórico se popularizó a través de la película titulada Inherit the Wind (en España Herederos del Viento). En ella, el abogado de Scopes, interpretado por Spencer Tracy, deja en ridículo al fiscal acusador mediante un bonito truco dialéctico: si la serpiente bíblica fue condenada a arrastrarse sobre el vientre, "¿ Tiene usted idea — preguntaba Tracy al fiscal — de cómo andaba la serpiente hasta entonces?» El fiscal se queda sin palabras. La ciencia, de nuevo, derrota a la religión. Y de nuevo Ruse $(2001,6)$ nos explica el trasfondo sociológico, no del juicio, que se zanjó prosaicamente con una multa de cien dólares anulada tras apelación, sino de la reconstrucción y utilización del mismo.

Una de las últimas batallas legendarias libradas por los dos contendientes supuestamente irreconciliables se produjo en Arkansas, años 80. Una ley estatal obligaba a impartir en la escuela tantas horas de biología evolucionista como de biología creacionista. La Cámara de Comercio y la Unión de Libertades Civiles Norteamericana (ACLU) promovieron un juicio en el que el juez tuvo que tomar una difícil decisión. Se vio obligado nada menos que a dirimir qué es y qué no es ciencia. En definitiva, la llamada biología creacionista no cuenta como tal, y 
no hay por qué hacerle sitio en la escuela entre las materias científicas. En el juicio intervino el propio Michael Ruse en condición de experto. También lo hicieron otros destacados evolucionistas como Stephen J. Gould y Francisco Ayala. Tal y como Ruse (2001, 4-5) declaró en el juicio «la ciencia creacionista no tiene las cualidades que distinguen a la ciencia de otras empresas [...] La ciencia creacionista no es ciencia».

Al calor de disputas como estas, y sobre todo de su reinvención ideológica, se han ido configurando las posiciones extremas actuales y se han ido mistificando las cuestiones de fondo. La ciencia creacionista, en efecto, no es ciencia. Tampoco lo son los argumentos antirreligiosos de autores como Richard Dawkins. Expongamos ahora brevemente estas posiciones extremas antes de pasar a la exploración del nuevo territorio para el diálogo.

\section{El creacionismo y los oráculos de la ciencia}

El creacionismo, literalmente, sería la doctrina conforme a la cual el mundo habría sido creado por Dios. El creacionismo suele reconocer al Dios creador también la condición de providente. Dios crea desde el principio el mundo a partir de la nada, lo cuida y lo mantiene en el ser. Hasta aquí no hay nada que pueda, ni remotamente, ser incompatible con el evolucionismo. De hecho, se trata de tesis independientes que se sitúan en planos distintos. Para verlo con claridad identifiquemos sus opuestos. El evolucionismo es una tesis que se mueve en el ámbito de la biología, y cuyo opuesto es el fijismo. Según el evolucionismo las distintas especies han evolucionado las unas a partir de las otras. Según el fijismo no es así, los seres vivos se reproducen siempre dentro de los lindes de una especie. De una especie no puede surgir otra. Por su lado, el creacionismo es una doctrina de carácter teológico, y tendría su opuesto o bien en el deísmo, que debilita el sentido de la creación y niega la providencia, o bien en el ateísmo, según el cual simplemente no hay Dios.

Un indicio claro de que nos hallamos ante tesis independientes es que históricamente se han dado todo tipo de combinaciones. Por ejemplo, el fundador de la biología, Aristóteles, podría ser calificado antes de fijista que de evolucionista, y, desde luego, no fue creacionista. Por su parte, algunos evolucionistas contemporáneos sostienen posiciones religiosas que podríamos 
clasificar dentro del creacionismo. Se puede citar como precedente el caso de Teilhard de Chardin, quien intentó dar un sentido teológico a la evolución. También hay, por supuesto, evolucionistas ateos y fijistas creyentes. Como se puede esperar, entre términos independientes se dan todas las combinaciones posibles.

Pero el término «creacionismo» no se ha hecho problemático por su contenido semántico original, sino por el uso que algunos le han dado como ariete contra el evolucionismo. Especialmente equívoco resulta cuando se adjetiva como «científico».

\subsection{Creacionismo científico y Diseño Inteligente}

El darwinismo en los Estados Unidos despertó siempre una cierta oposición de base entre religiosa y populista. Sobre todo en algunos círculos protestantes, tendentes a una lectura literalista de la Biblia, fue visto como una doctrina peligrosa y deletérea, cuando no directamente satánica. Desde los comienzos del siglo pasado, los opositores al evolucionismo se atrincheraron en la lectura del Génesis al pie de la letra. La obra de George McCready Price, The new Geology, publicada en 1923, constituyó, en este sentido, un punto de referencia. Su estela fue seguida por otros, como el biólogo Harold W. Clark, quien en 1929 calificó la obra de su maestro con el rótulo de "creacionista». A partir de entonces la doctrina así denominada ha estado siempre presente en la sociedad americana, si bien en círculos más bien minoritarios.

Un punto de inflexión importante lo constituye juicio al maestro Scopes, al que antes nos hemos referido. A partir del mismo los llamados creacionistas entendieron que tenían que dar la batalla también en el terreno propio del adversario, es decir, en el campo de la ciencia. El rearme intelectual llegó con la publicación en 1961 del libro The Genesis flood, firmado por John Whitcomb y Henry M. Morris. El propio Morris fundó en California el Institute for Creation Research (ICR), del que parten la mayoría de las publicaciones que defienden el creacionismo científico. A este centro se ha unido la Creation Research Society, en Missouri. Su objetivo es la búsqueda, por métodos que puedan considerarse al menos formalmente científicos, de evidencias contrarias al evolucionismo y favorables a la interpretación literal de la Biblia. 
En este punto, los llamados creacionistas científicos se sintieron con fuerza suficiente como para pedir que en las clases de biología se dedicasen tantas horas a sus doctrinas como al evolucionismo. Su propuesta prosperó en Arkansas durante un tiempo, entre los dos mandatos del gobernador Clinton. Hasta que el 5 enero de 1982, el juez William R. Overton sentenció que el creacionismo no pertenecía al dominio de la ciencia, por más que se autodenominase científico.

De nuevo estamos ante un punto crucial. El evolucionismo gana en los tribunales, sí, pero no por ello se extingue la oposición popular y religiosa al mismo. La razón para excluir al creacionismo de las clases de biología reside en su carácter religioso, según la corte de Arkansas. De modo que el movimiento creacionista se reviste a partir de aquí de una nueva apariencia y se acoge a una nueva denominación, Diseño Inteligente (DI), con el fin de evitar toda apariencia de doctrina religiosa. Se puede decir que una parte de los americanos siguen percibiendo el evolucionismo como una amenaza para su religión. A esta percepción contribuye, sí, el sesgo literalista de algunas iglesias protestantes, pero también las declaraciones más bien desafortunadas de algunos evolucionistas. El caso más significativo es el de Richard Dawkins (1989), quien llegó a decir que las personas que no creen en la evolución son «estúpidas, malvadas o locas» («stupid, wicked or insane»), lo cual no constituye precisamente la forma más educada de reconducir las cosas. Obviamente, en sentido contrario, la acusación de satanismo recibida por Dawkins tampoco lo es.

El centro más activo del DI es Discovery Institute, situado en Seattle y fundado en 1990. Entre las figuras más destacadas del DI encontramos al abogado Phillip E. Johnson, quien publicó en 1991 el libro Darwin on trial. En el Discovery Institute trabajan otros estudiosos afines al DI, como Stephen Meyer, filósofo de la ciencia y teólogo, Michael Behe, bioquímico, y el matemático William A. Dembski, que actúa como portavoz del movimiento. De algún modo el DI nos devuelve al reloj de Paley. Esta vez la estrategia consiste en hablar del reloj, pero no del relojero. O sea, se trata de mostrar que la teoría de la evolución por selección natural no da cuenta adecuadamente del diseño de los seres naturales. La teoría del DI, en cambio, resultaría una alternativa científica aceptable.

Por supuesto, la idea de diseño apunta a un diseñador, como el reloj al relojero, pero los partidarios de la misma prefieren evitar cualquier pronunciamiento teológico acerca de la naturaleza del diseñador. Entre los argumentos que mane- 
jan con mayor frecuencia en contra del evolucionismo está su peculiar interpretación del principio antrópico, según el cual las constantes físicas críticas del universo están calibradas de modo que la vida humana sea posible. Por otro lado, esgrimen la idea de que la complejidad y armonía de algunos organismos y de algunos órganos es inexplicable de otro modo que no sea a través del DI. Efectivamente, estos argumentos no carecen de cierta fuerza retórica, y en distintas versiones vienen siendo discutidos desde los tiempos de Darwin. Al propio científico británico le preocupaba la posibilidad de explicar mediante selección natural la aparición de órganos tan complejos como el ojo, donde unas partes carecen de sentido funcional sin las otras. Sin embargo, también parece obvio que al menos una parte de las estructuras orgánicas tienen un diseño mejorable o directamente defectuoso o claramente oportunista.

Nada habría que decir si los partidarios del DI presentasen un debate leal en términos científicos, pero de hecho no es así. Se presentan al mismo tiempo como promotores de un proyecto científico y como defensores de una forma de entender la acción divina. Es fácil entender por qué no pueden prescindir de ninguno de los dos aspectos. El primero les habilitaría en el campo de la ciencia y la enseñanza, mientras que el segundo es el que otorga al DI un cierto atractivo para las personas religiosas. La cuestión es que no se pueden tener las dos cosas a un tiempo, «un modo de entender la acción divina —señalan Giberson y Artigas (2007, 14) - no puede ser un programa de investigación científica». El creacionismo, en su versión del DI, parece estar hoy día en una situación imposible.

Curiosamente, la supuesta incompatibilidad entre creacionismo y evolucionismo, tal y como la predican los partidarios del DI, ha sido explotada también en sentido contrario, hasta convertir las teorías darwinistas en argumentos teológicos contrarios a la fe en un Dios creador. En esto sí que coinciden los partidarios del DI con ciertos «oráculos de la ciencia». Ambas partes consideran incompatible el evolucionismo y la religión.

\subsection{Oráculos de la ciencia}

La expresión «oráculos de la ciencia» se ha difundido a partir de la publicación por parte de la Oxford University Press del libro Oracles of Science, firmado conjuntamente por Karl Giberson y Mariano Artigas (2007). Según estos pen- 
sadores, el típico oráculo de la ciencia es un científico brillante y laureado, con grandes dotes de comunicador, que ofrece al gran público lo que acaba por convertirse en la imagen social de la ciencia. Este tipo de intelectual acostumbra a culminar sus obras de divulgación, por lo demás rigurosas, con algunas declaraciones más o menos enigmáticas, en estilo clásicamente oracular, a través de las que hace llegar a las masas sus puntos de vista sobre el origen y el sentido de la vida, sobre el universo en su conjunto, sobre la moral y la política, sobre lo humano y lo divino. Dichas declaraciones, carentes de apoyo empírico, que de ninguna manera se atrevería a incluir en sus artículos preparados para revisión por pares, son presentadas de improviso, como supuestos corolarios de cientos de páginas llenas de datos científicos y metáforas didácticas. Y el caso es que estas declaraciones oraculares muchas veces calan más en la opinión pública que cualquier argumento sólido.

"Cuanto más comprensible parece el universo, más sin sentido parece», es un hermoso ejemplo de sentencia oracular, escrita por el físico Steven Weinberg. Entre los oráculos de la ciencia, Giberson y Artigas, colocan también a Carl Sagan, Stephen Hawkins, Edward O. Wilson, Stephen Jay Gould y Richard Dawkins. Las obras de estos, en su conjunto, dan la impresión de que la ciencia se ocupa principalmente de la cuestión de los orígenes del universo, de la vida y del ser humano. Además ofrecen la idea de que existe un conflicto entre ciencia y religión. Lo cierto, afirman Giberson y Artigas, es que la ciencia se ocupa principalmente de cuestiones más cercanas y prácticas que la del origen, como se deriva de la lectura de los índices de cualquier revista especializada. Por otro lado, la actitud de los científicos ante la religión es comparable a la de cualquier otro grupo sociológico, lo cual demuestra que no existe especial conflicto. Quizá esta simple constatación podría servir para rebajar la tensión de ciertos debates, como el que nos ocupa.

Tres de los científicos estudiados son físicos, otros tres biólogos. Aquí nos interesan estos últimos. Entre ellos Wilson y Gould muestran posiciones muy matizadas en cuanto a las relaciones entre evolucionismo y religión. El tercer biólogo, Richard Dawkins, nos servirá como ejemplo y personificación de la postura mantenida por algunos evolucionistas, frontalmente contraria al fenómeno religioso. Este tipo de actitud sirve de combustible para un debate inútil y de coartada para el despliegue de estrategias mistificadoras como las del DI. 
Las ideas de Dawkins respecto a la religión empiezan a expresarse con claridad una vez que introduce en su jerga el concepto de «meme». Un meme sería algo así como una unidad de información y reproducción cultural, una idea, como por ejemplo la que expresa la frase de Luther King «I have a dream», o la canción de los Beatles "Yesterday». Un meme prolifera o se extingue, de modo análogo a los genes, mediante una dinámica darwinista. Pues bien, según esto, la religión estaría constituida por un conjunto de memes perjudiciales, auténticos «virus de la mente» ${ }^{4}$.

Su visión negativa de la religión, que aparecía de modo tangencial en El gen egoista (The selfish gene, 1976), pasa al centro de su producción intelectual con El relojero ciego (The blind watchmaker, 1986), donde responde al argumento del diseño y da por periclitadas las funciones que tradicionalmente las religiones atribuían a Dios. Dios ya no es necesario, está el darwinismo en la versión de Dawkins para explicar la complejidad y funcionalidad de los organismos. Incluso el sentido, o más bien el sinsentido de la vida, así como la existencia del mal quedan explicados a través del flujo del ADN en su El río del edén (River out of Eden, 1995). El tono agresivo contra la religión se hace aun más patente en sus últimos libros, como El capellán del Diablo (A Devil's chaplain, 2003) y El espejismo de Dios (The God delusion, 2006). Insiste en general en la idea de la religión como virus de la mente, como una enfermedad que infecta a los creyentes, e incluso acaba culpando a la religión, así, en general, del ataque contra las Torres Gemelas. Ni que decir tiene que los memes de la ciencia son tan correctos como incompatibles con los de la religión, según la particular ideología cientificista de Dawkins.

Las afirmaciones antirreligiosas de Dawkins han generado una intensa polémica. No es posible aquí dar cuenta por extenso de la misma. Baste saber que Dawkins ha sido respondido por diversos intelectuales desde los más diversos ángulos. Intelectuales creyentes han polemizado con él (McGrath, 2005; Eagleton, 2009; Lennox, 2009). También eximios darwinistas, como Gould (1999) o Ruse (2001). Sólo los creacionistas pueden haber recibido con alegría las descalificaciones de Dawkins. En efecto, quienes quieren forzar la incompatibilidad entre ciencia y religión, quienes prefieren presentar la ciencia como una amenaza para sus creencias religiosas, pueden darse un auténtico festín con las afirma-

${ }^{4}$ La expresión procede del título de un texto de Dawkins de 1991, posteriormente incluido en Dawkins (2003). 
ciones de Dawkins. Dicho de otro modo: las posiciones confrontadas, creacionismo por un lado y cientificismo por el otro, en realidad se generan y alimen$\tan$ mutuamente.

\section{Un territorio para el diálogo}

Entre estas posiciones extremas que hemos delineado, emerge hoy con mucha fuerza un territorio para el acuerdo, la colaboración y el debate constructivo. Desde el lado del darwinismo y también desde el lado de la religión tenemos textos recientes muy significativos. Vamos a centrarnos en tres de ellos, los cuales por distintas razones resultan relevantes, y conjuntamente ofrecen una imagen clara del nuevo territorio para el diálogo. Me refiero, en primer lugar, al libro de Michael Ruse titulado ¿Puede un darwinista ser cristiano? La relación entre ciencia y religión (2001). Tras analizar cuidadosamente la cuestión que plantea el título, Ruse concluye favorablemente.

En segundo lugar me referiré al libro de Francisco Ayala que lleva por título Darwin y el Diseño Inteligente. Creacionismo, cristianismo y evolución (2006). Aquí, el autor defiende la compatibilidad de darwinismo y cristianismo, pero lleva el argumento más allá, hasta el punto de afirmar que es la doctrina del Diseño Inteligente la que en realidad resulta incompatible con la teología cristiana.

Por último, revisaremos las aportaciones del físico y teólogo español Mariano Artigas, recogidas en un libro que escribió, poco antes de su muerte, junto a Thomas F. Glick y Rafael A. Martínez: Negotiating Darwin (2006). Tras la apertura al público en 1998 de los archivos del Santo Oficio, Artigas emprendió la búsqueda de los documentos que muestran cómo reaccionó al Vaticano ante las teorías darwinistas en los años inmediatamente posteriores a la publicación de las mismas. Las conclusiones de dicho estudio resultan también una aportación valiosa como referencia para allanar el territorio del diálogo.

\subsection{Michael Ruse sobre darwinismo y cristianismo}

No es que estas posiciones conciliatorias sean nuevas. En realidad existe una larga tradición en este sentido. «Uno de los primeros hombres que hablaron públi- 
camente a favor del darwinismo — dice Michael Ruse $(2001,9)$ en referencia al Reverendo Baden Powell— no sólo era cristiano, sino clérigo anglicano [...] Otros se unieron a las opiniones expresadas por Baden Powell: a un lado del Atlántico, el Reverendo Charles Kingsley [...] en el otro lado del Atlántico, el principal portavoz del darwinismo en Norteamérica, el catedrático de botánica

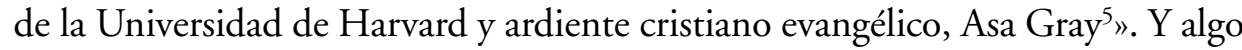
parecido puede decirse del teólogo oxoniense anglocatólico Aubrey Moore, quien escribió a favor del darwinismo a finales del siglo XIX.

Ruse detecta intentos de armonización no sólo desde el lado de la religión, sino también desde el punto de vista del evolucionismo. Entre los más importantes científicos evolucionistas se debe citar, sin duda, al inglés Ronald Fisher, así como al ruso-americano Theodosius Dobzhanky. «Ambos eran —recuerda Ruse $(2006,10)$ - ardientes cristianos», anglicano el uno y ortodoxo el otro. Según Fisher, el mensaje del darwinismo para la persona religiosa vendría a ser que la creación no ha concluido, que la acción de Dios sigue vigente y presente hoy día a través del proceso evolutivo. Desde el punto de vista moral también tiene el darwinismo un mensaje útil para el creyente. Al parecer Dios nos habría encomendado el cuidado — más que el dominio- de su obra y la colaboración en su empresa creadora. Por su parte, Dobzhansky apunta en la misma dirección en una de sus cartas: «No veo — afirma — cómo escapar a la idea de que Dios actúa no sólo en rachas de intervenciones milagrosas, sino en todos los acontecimientos importantes e insignificantes, espectaculares y ordinarios» (cit. en Ruse, 2001, 10).

A las citas precedentes Ruse podría haber añadido la opinión de otro de los padres de la teoría sintética de la evolución, el paleontólogo Georges G. Simpson $(1983,211)$, quien recuerda que muchos profesores, religiosos y laicos, aceptan la evolución como un hecho. "Y muchos evolucionistas — afirma — son hombres de profunda fe. Además, los evolucionistas pueden ser también creacionistas».

Se podría alegar que la evolución darwinista carece de toda orientación o sentido, que no posee guía ni dirección. No es este el lugar para entrar a fondo en cuestión tan compleja. Nos movemos aquí en el plano de la plausibilidad. La

5 Acerca de la correspondencia entre Charles Darwin y Asa Gray, que con frecuencia aborda cuestiones teológicas, puede verse Miles, 2001. 
tesis que Ruse quiere hacer plausible es que el darwinismo y el cristianismo son compatibles. El hecho de que algunos de los principales creadores de la teoría sintética de la evolución hayan pensado así constituye, desde luego, un argumento de peso. Se hace difícil atribuir a personas como Fisher, Dobzhansky o Simpson, quienes han puesto en pie la versión del darwinismo más comúnmente aceptada hoy día, una intelección errónea de sus consecuencias. Pero además es que el debate acerca del sentido de la evolución no está en absoluto cerrado. Puede consultarse a este respecto el libro de Robert J. Richards (1992), The meaning of evolution. Según el autor, el modelo de la evolución darwinista fue tomado de la embriología, y por lo tanto de un proceso con sentido. Sólo una posterior reconstrucción ideológica del darwinismo — sostiene Richards— lo aproximó a la perspectiva nihilista. Lo importante aquí no es dirimir el debate que desencadenó el libro de Richards, sino simplemente constatar que el darwinismo puede ser leído en un sentido no nihilista, del mismo modo que el cristianismo puede ser compatible con teorías no fijistas.

Pero no sólo los clásicos de la teoría sintética de la evolución se muestran conciliadores. Entre los científicos darwinistas más recientes Michael Ruse cita a S. J. Gould. Para Gould no existe incompatibilidad entre evolución y religión por la sencilla razón de que no hay solapamiento. Tratan de cosas distintas y no pueden entrar en conflicto. Tampoco realmente en diálogo, pues poco podrían obtener la una de la otra. Esta tesis fue denominada por Gould (1999) Non-Overlapping Magisteria (NOMA).

No obstante, Ruse quiere ir más allá de la mera coexistencia pacífica sugerida por la tesis NOMA de Gould. Según Ruse (2001, 264): «Aunque la comparación entre el darwinismo y el cristianismo puede ser difícil y desafiante, también es estimulante y fructífera. Mantengo - he mantenido - una y otra vez que lo que podrían parecer barreras firmes para que la misma persona pueda ser darwinista y cristiana al tiempo resultan ser, cuando se examinan, precisamente los puntos en los que se puede avanzar y se puede lograr entendimiento». Esta es no sólo la tesis central, sino también la estrategia de Ruse. Caracteriza primero la esencia del darwinismo, después la del cristianismo, e identifica a continuación los posibles puntos de conflicto: cuestiones como las del origen de la vida, el origen del ser humano, el problema del sentido y del diseño, el problema del mal y el dolor, el de la libertad y la moral. Precisamente en estos campos detecta Ruse posibilidades de diálogo y mutua colaboración. 
Es remarcable la actitud de humildad intelectual recomendada por Ruse $(2001,265)$ para ambos interlocutores, y adoptada por él mismo: «Si se es darwinista, cristiano, o las dos cosas a la vez, recuérdese que somos meros seres humanos y no Dios. Somos primates de tamaño medio, con adaptaciones que nos hicieron bajar de los árboles y vivir en las llanuras en grupos sociales. No tenemos las capacidades que necesariamente nos permitirían escudriñar los misterios últimos. Aunque sólo sea eso, estas reflexiones nos deben hacer ser un poco más modestos acerca de lo que podemos y no podemos conocer, y ser un poco humildes ante lo desconocido. Nuestras limitaciones no hacen que el cristianismo sea obligatorio, ni siquiera plausible, pero hacen necesarias la tolerancia y el aprecio de los que van más allá de la ciencia, aunque nosotros no podamos seguirlos». Sólo desde una tal actitud es posible el entendimiento, mientras que el choque se produce cuando predomina la arrogancia, ya sea en su modo fundamentalista o cientificista.

\subsection{Ayala sobre Darwin y el Diseño Inteligente}

Entre los puntos de fricción/colaboración detectados por Ruse, está — digámoslo al modo grandilocuente- el problema del bien y del mal. De un modo un poco más prosaico, la cuestión es que una religión que remite a un Dios creador, providente y bueno, tiene problemas para explicar la presencia sobre la Tierra del mal en sus diversas variantes. Y, en contraposición, una teoría evolutiva que fía todo al juego de azar y necesidad, de variación aleatoria más selección, puede tener análogos problemas para explicar el progreso evolutivo, el crecimiento de la complejidad, la indudable armonía y belleza de los vivientes y de los ecosistemas. Al fin y al cabo, muchas de las formas más elementales y primitivas de la vida ya resultaban aptas para la supervivencia y la reproducción, tanto o más que algunas formas más evolucionadas y complejas. Ya se puede entrever la posible línea de colaboración en este terreno.

Me apresuro a decir que la tradición teológica no ha necesitado de las teorías darwinistas para abordar el problema del mal. Es uno de los tópicos sobre los que más se ha escrito. El dolor, el sufrimiento, el error, el mal moral, la enfermedad, la propia muerte, constituyen para el teólogo cristiano materia de obligada reflexión. Por otro lado, las adaptaciones, armonía e incluso belleza de la vida no han sido rasgos ajenos a las preocupaciones darwinistas. Con todo, sea 
uno darwinista, cristiano, ambas cosas o ninguna de las dos, hemos de reconocer la limitada comprensión que tenemos tanto de la miseria como de la grandeza, ambas innegables, de nuestro mundo natural y humano. Tan sólo quiero sugerir que en este juego de simetrías se advierte un territorio prometedor para la colaboración intelectual entre evolucionismo y religión, sin que se requiera en absoluto que ambas posiciones lleguen a unir sus suertes. Algo así es lo que defiende Francisco Ayala, uno de los más importantes biólogos evolucionistas y ex-presidente de la American Association for the Advancement of Science, en su libro Darwin y el diseño inteligente.

El texto de Ayala está construido como una crítica sostenida a las doctrinas del Diseño Inteligente, que son, en opinión del autor, el nuevo disfraz del creacionismo antievolucionista. En el fondo, el DI está pensado no como teoría científica, aunque a veces se presente como tal, sino como un modo de salvar una cierta lectura literalista de la Biblia. Ayala trata de mostrar que tal lectura no es en absoluto la única posible. Trae para ello a sus páginas las declaraciones de algunas personalidades muy relevantes dentro del ámbito cristiano. «Santo Tomás de Aquino (1224-1274) — nos dice Ayala $(2006,19)$ —, siguiendo una larga tradición cristiana que se remonta al menos hasta san Agustín (354-430), distinguía dos fuentes de conocimiento: la razón y la Revelación Divina». Esta es la base de lo que más arriba hemos denominado autonomía. La base sobre la cual se puede hacer ciencia, filosofía y teología sin mutuas dependencias jerárquicas.

«Según san Agustín, en su comentario sobre el libro del Génesis, —continúa Ayala (2006, 19) - los cristianos no deben tratar de resolver cuestiones científicas con las Sagradas Escrituras». Recoge, a partir de ahí dos citas muy significativas para la discusión posterior con el DI, la primera del propio san Agustín: «Si sucede que la autoridad de las Sagradas Escrituras parece oponerse a conocimientos obtenidos por un razonamiento claro y seguro, significa que la persona que interpreta las Escrituras no las comprende correctamente» (cit. en Ayala, 2006, 20). La segunda cita es actual y procede del anterior papa, Juan Pablo II: «La Biblia nos habla del origen del universo y su creación, no para proporcionarnos un tratado científico sino para establecer las correctas relaciones del hombre con Dios y con el universo [...] Las Sagradas Escrituras simplemente desean declarar que el mundo fue creado por Dios, y con el fin de enseñar esta verdad se expresan en los términos de la cosmología conocida en los tiempos del escritor sagrado» (cit. en Ayala, 2006, 175). 
En la misma línea del texto citado por Ayala, es conocida la declaración hecha por Juan Pablo II el 22 de octubre de 1996 ante la Academia Pontificia de Ciencias: «El conocimiento científico nos ha llevado a darnos cuenta de que la teoría de la evolución ya no es una mera hipótesis. De hecho, es notable que esta teoría haya sido progresivamente aceptada por los investigadores, como consecuencia de una serie de descubrimientos en diversos campos del conocimiento. La convergencia, ni buscada ni fabricada, de los resultados de trabajos llevados a cabo de forma independiente es en sí misma un argumento importante a favor de la teoría» (cit. en Ayala, 2006, 173).

Juan Pablo II recordaba en su alocución el precedente de la publicación en 1950 de la Encíclica Humanis Generis, en la que también se hablaba positivamente de las teorías evolucionistas. Por su parte, Ayala continúa con la aportación de declaraciones análogas procedentes de la Asamblea General de la Iglesia Presbiteriana (1982), de la Conferencia de Rabinos Americanos (1984) y de la Federación Mundial Luterana (1965). Esta última utiliza la acertada expresión «sana tensión de respeto mutuo» para caracterizar las relaciones entre ciencia y religión. Y a estas declaraciones se suman las efectuadas, también en el sentido de la compatibilidad por algunas de las más importantes instituciones científicas norteamericanas, como la National Academy of Science y el Institute of Medicine (AA. VV., 2008).

Esa tensión de respeto mutuo excluye, por supuesto, las posiciones propias del DI. También las declaraciones oraculares de autores como Dawkins. Respecto de las mismas, Ayala (2006, 178-9) escribe: «Hay una contradicción monumental en estas afirmaciones. Si el compromiso que la ciencia tiene con el naturalismo no le permite derivar valores, significados o propósitos a partir del conocimiento científico, sin duda tampoco le permite negar su existencia. Podemos conceder a estos autores [Richard Dawkins, William Provine, Douglas Futuyma] su derecho a pensar como quieran, pero no tienen ninguna autoridad para basar su filosofía materialista en los logros de la ciencia. Resulta irónico que dichos autores, en realidad, estén avalando las creencias de los defensores del DI que argumentan que la ciencia es inherentemente materialista».

Pero la jugada maestra que se reserva Ayala para refutar el DI consiste en presentarlo precisamente como mala teología, incompatible incluso con la idea de un Dios creador y providente. Es así, según Ayala, debido a que el mundo con- 
tiene buenas muestras de errores de diseño. Por citar sólo uno: «Consideremos — pide Ayala (2006, 158) — la mandíbula humana. Tenemos demasiados dientes para el tamaño de la mandíbula, de modo que hay que extraer las muelas del juicio y los dentistas se ganan bien la vida corrigiendo el resto de la dentadura. ¿Querríamos acusar a Dios por esta metedura de pata? Un ingeniero humano lo habría hecho mejor». Podemos, en cambio, dar una buena explicación de esta imperfección en términos evolucionistas. En realidad la mandíbula pequeña se corresponde con un cerebro grande que en conjunto tienen que pasar a través del canal del parto. Sin embargo, la remodelación evolutiva del cráneo humano no ha llegado al detalle de ajustar el número de piezas dentales. «En el pasado concluye Ayala $(2006,159)$ - los teólogos lucharon contra el problema de la disfunción porque ellos pensaban que tenía que ser atribuida al diseño de Dios. La ciencia, para gran alivio de los teólogos, proporciona una explicación que de forma convincente atribuye los defectos, las deformidades y las disfunciones a causas naturales».

Por supuesto, la idea de Ayala tiene sus propias limitaciones y no zanja definitivamente el problema del mal, ni creo que él mismo lo haya pretendido. Un creyente se podría preguntar todavía por qué Dios consiente una dinámica natural que conduce a imperfecciones. Esta misma objeción quizá tenga respuesta. No trato ahora de abordar el debate. En la parte que afecta a mi argumento la posición de Ayala es clara y plausible. Traza unas relaciones de compatibilidad y de autonomía, pero que apuntan también un poco más allá hacia un diálogo colaborativo.

\section{3. "Negotiating Darwin»}

El libro Negotiating Darwin, firmado conjuntamente por Mariano Artigas, Thomas F. Glick y Rafael A. Martínez, constituye también una aportación valiosa para el trazado de estas relaciones de compatibilidad entre ciencia y religión, entre darwinismo y cristianismo, a las que nos venimos refiriendo. Como es sabido, el papa Juan Pablo II abrió a la investigación los archivos del Santo Oficio en 1998. Mariano Artigas trabajó en los mismos con el objetivo de establecer sobre bases documentales la reacción del Vaticano ante la publicación de la teoría darwinista de la evolución. El libro referido presenta y valora los documentos pertinentes producidos desde 1877 hasta el comienzo del siglo XX. 
Se documentan seis casos de intelectuales católicos que se propusieron -en la terminología de la época - «armonizar» evolucionismo y cristianismo. Se trata de Raffaello Caverni, Dalmace LeRoy, John A. Zahm, Geremia Bonomelli, John C. Hedley y Georges J. Mivart. Los documentos revisados tienen que ver con las publicaciones de estos autores y las reacciones que las mismas suscitaron en el Vaticano. Para nuestro argumento, ya es significativo el hecho de que desde fechas tan tempranas un buen número de intelectuales católicos de distinta procedencia postulasen la compatibilidad entre evolucionismo y cristianismo.

En cuanto a la reacción del propio Vaticano, las conclusiones expuestas en Negotiating Darwin son más bien sorprendentes, incluso para los propios autores, que no sabían cuando iniciaron su labor lo que encontrarían en los archivos vaticanos: «La investigación —nos dicen Artigas, Glick y Martínez $(2006,4)$ nos llevó a conclusiones inesperadas. Aunque desde fuera uno pudiera muy bien pensar que el Vaticano adoptó una cuidada política respecto del evolucionismo, para nuestra sorpresa, en cierto sentido no hubo ninguna política. Las acciones de las autoridades respondieron a circunstancias particulares, y no a ningún plan cuidadosamente diseñado». Lo único que se puede decir con claridad es que «del Vaticano no salió ninguna condena oficial, a pesar del hecho de que el evolucionismo provocó tensiones severas» (Artigas at al., 2006, 4).

Podríamos explicarlo del siguiente modo: en realidad sí que hubo una tenue línea política en la reacción vaticana ante el evolucionismo. Esa tenue política se resumiría simplemente en evitar a toda costa un segundo affaire Galileo. «Aunque el concepto de evolución tomó forma en la segunda mitad del siglo XIX, tras la publicación de El origen de las especies de Charles Darwin en 1859, su recepción por parte de la Iglesia Católica de Roma estuvo relacionada con la condena a Galileo de 1633. Las autoridades católicas miraban el evolucionismo con sospecha pero temían condenarlo [...] La sombra de Galileo estuvo siempre presente» (Artigas at al., 2006, 6).

En términos más generales, los autores sostienen que su investigación refuerza la idea de relaciones históricamente complejas entre ciencia y religión. «Hasta hace poco — nos dicen — la relación entre ciencia y religión ha sido considerada como un continuo y perpetuo conflicto. En nuestros días, la 'tesis de la complejidad' está ganando apoyos [...] Nuestras conclusiones no pueden reducirse a una tesis simple. De hecho, si alguna tesis debe ser subrayada, nosotros 
querríamos enfatizar que las autoridades del Vaticano no siguieron una agenda fija, una conclusión muy en acuerdo con la tesis de la complejidad» (Artigas at al., 2006, 5).

\section{Conclusión}

Desde un punto de vista histórico, hemos visto que las relaciones entre el evolucionismo y la religión - y más específicamente entre el darwinismo y el cristianismo - han sido sumamente complejas. En ningún momento ha existido una oposición frontal inexorable entre la religión cristiana y la biología evolucionista. Tampoco se puede afirmar una beatífica convivencia sin tensiones. De hecho, algunos cristianos y algunos darwinistas concuerdan en el desacuerdo. Es decir, unos y otros, creacionistas y cientificistas, propugnan la incompatibilidad. Se han dado, en cambio, múltiples intentos de armonización, compatibilización e incluso diálogo. Estos intentos han tenido presencia en el pasado, pero aun más en el momento actual. La literatura más reciente sobre el asunto está jugando la carta de la compatibilidad. Y eso desde posiciones muy diversas, como hemos visto. Es sumamente significativo que los expertos darwinistas que intervinieron en el famoso juicio de Arkansas, Michael Ruse, Francisco Ayala y Stephen J. Gould, en cuyas declaraciones se basó la sentencia del juez Overman, se hayan expresado posteriormente todos ellos en términos conciliadores. Los tres piensan que el evolucionismo es perfectamente compatible con la religión, e incluso dos de ellos afirman la posibilidad de un diálogo fructífero.

Entre las lecciones que podemos obtener de estos episodios, registremos la siguiente: las relaciones entre ciencia y religión no están selladas por ningún destino fatal de incompatibilidad. No hay nada en la naturaleza de ambas que obligue a la confrontación. Tampoco son relaciones sencillas ni carentes de tensión. Que esta tensión se resuelva hacia el polo de la confrontación o hacia el polo del diálogo depende tan sólo de la libertad de las personas. Partiendo del caso concreto del darwinismo, aquí se ha argumentado a favor de la compatibilidad entre ciencia y religión. Compatibilidad entendida como empresa, como horizonte, como búsqueda guiada por dos principios: el de la mutua autonomía y el del diálogo cooperativo. 


\section{Bibliografía}

AA.VV., 2008. Science, evolution, and creationism / National Academy of Sciences, Institute of Medicine. Washington, D.C.: National Academies Press.

AGAZZI, E., 1992. Il bene, il male e la scienza. le dimensioni etiche dell'impresa scientificotecnologica, Milán: Rusconi.

Artigas, M., Glick, T. F., MartíneZ, R. A., 2006. Negotiating Darwin. The Vatican confronts evolution (1877-1092), Baltimore: The Johns Hopkins University Press.

Ayala, F. J., 2006. Darwin and Intelligent Design, Minneapolis: Fortress Press. Traducción española de Coll, M. A., 2007. Darwin y el Diseño Inteligente. Creacionismo, cristianismo y evolución, Madrid: Alianza.

BOWLer, P., 1983. The eclipse of Darwinism, Baltimore: The Johns Hopkins University Press. Traducción española de FACI, J., 1985. El eclipse del darwinismo, Barcelona: Labor.

CHALmers, R., 2004 [1844]. Vestiges of the natural history of creation, Bristol: Thoemmes Press.

DARWIN, C., 1974 [1859]. El origen de las especies, Barcelona: Ediciones Petronio.

- 1973 [1871]. El origen del hombre, Barcelona: Ediciones Petronio.

- 1993 [1887]. Autobiografía, Madrid: Alianza.

DAWKInS, R., 1986. The blind watchmaker, Londres: Longman. Traducción española de VIVES, J., 1988. El relojero ciego, Barcelona: Labor.

3/43/41989. «Book Review of Donald Johanson and Maitland Edey's Blueprint», New York Times, section 7, 9 de abril de 1989.

- 1995. River out of Eden: A Darwinian view of life, Londres: Weidenfeld and Nicolson.

- 2003. A Devil's chaplain, Londres: Weidenfeld and Nicolson.

- 2006. The God delusion, Boston: Houghton Mifflin.

Eagleton, T., 2009. Reason, faith and revolution, New Haven: Yale University Press.

Giberson, K., ARTIGAS, M., 2007. Oracles of Science. Celebrity scientists versus God and Religion, Oxford: Oxford University Press.

Gould, S. J., 1999. Rocks of ages: Science and Religion in the fullness of life, New York: Ballantine. 
Johnson, P. E., 1991. Darwin on trial, Washington D. C.: Regnery Gateway.

LenNox, J. C., 2009. God's undertaker. Has Science buried God?, Oxford: Lion Hudson.

McGraTh, A. E., 2005. Dawkins' God: Genes, memes and the meaning of life, Oxford: Blackwell.

MiLES, S. J., 2001. «Charles Darwin and Asa Gray Discuss Teleology and Design», PSCF 53, 196-201.

NúÑEz De Castro, I., 1996. «Ateísmo o agnosticismo de Charles Darwin», Proyección, 43, pp. 251-264.

PALEY, W., 1819 [1802]. Natural Theology, or evidences of the existence and attributes of the Deity collected from the appearances of Nature, 4 vols., Londres: Rivington.

RICHARD, R. J., 1992. The meaning of evolution. The morphological construction and ideological reconstruction of Darwin's theory, Chicago: Chicago University Press.

Ruse, M., 2001. Can a Darwinian be a Christian? The relationship between Science and Religion, Cambridge: Cambridge University Press. Traducción española de PÉREZ SEDEÑO, E. y Bustos, E., 2007. ¿Puede un darwinista ser cristinano? La relación entre Ciencia y Religión, Madrid: Siglo XXI.

Simpson, G. G. 1983, Fossils and the History of Life. New York: Scientific American Library W H Freeman \& Co. Traducción española de VILLA, E., 1985. Fósiles e historia de la vida, Barcelona: Labor.

Recibido: 1/09/2009

Revisado: 28/09/2009 